\title{
Tratamiento de los deberes constitucionales de la persona en el Perú: Una introducción
}

\author{
Gonzalo J. Monge Morales*
}

Resumen. - Se dice que "así como tenemos derechos, tenemos deberes" o que "a todo derecho le corresponde un deber". ¿Esto es cierto? ¿La Constitución consagra deberes igual de exigibles que los derechos? A lo largo de la historia y hasta la fecha, los deberes de la persona han sido relegados a un lugar secundario en el Derecho Constitucional y en el Derecho Procesal Constitucional. Es hora de rescatarlos del olvido. Mediante un análisis preliminar e introductorio, el autor plantea que los deberes constitucionales: (i) son imprescindibles para el constitucionalismo contemporáneo; (ii) no son solo obligaciones morales, sino que son jurídicamente exigibles; $y$, (iii) que deben ser exigibles jurisdiccionalmente. Surgen muchas dudas e interrogantes sobre el tema, pero no todas pueden ser absueltas de inmediato. Este es un análisis introductorio sobre su tratamiento en el régimen constitucional peruano.

\begin{abstract}
It is said that "just as we have rights, we have duties" or that "every right has a duty". Is this true? Does the Constitution establish duties as enforceable as rights? Throughout history and to date, the duties of the person have been relegated to a secondary place in Constitutional Law and in Constitutional Procedural Law. It is time to rescue them from oblivion. Through a preliminary and introductory analysis, the author states that constitutional duties: (i) are essential for contemporary constitutionalism; (ii) they are not only moral obligations, but are legally enforceable; and, (iii) that they must be legally enforceable. Many doubts and questions arise on the subject, but not all of them can be immediately answered. This is an introductory analysis about its treatment in the Peruvian constitutional regime.
\end{abstract}

Palabras claves. - Deberes - Deberes Constitucionales - Derecho Constitucional Derecho Procesal Constitucional - Teoría General del Derecho

Keywords. - Duties - Constitutional Duties - Constitutional Law - Constitutional Procedural Law - General Theory of Law

\footnotetext{
Abogado por la Pontificia Universidad Católica del Perú (PUCP). Ex Editor General de THËMIS-Revista de Derecho. Adjunto de Docencia en la Facultad de Derecho de la PUCP de los cursos Derecho Procesal Constitucional y Personas Jurídicas. Asociado Senior del Estudio Echecopar, member firm of Baker \& McKenzie International. Miembro fundador y ex Co-Coordinador General de Perspectiva Constitucional. Miembro de la Asociación Constitucionalismo Crítico. Becario Fulbright 2021-2022 (Harvard Law School). Contacto: gmonge@pucp.edu.pe
} 


\section{Presentación: El objetivo de este artículo}

Cuando pensamos en "deber", se nos vienen a la mente términos tales como "responsabilidad" u "obligación". Es decir, "algo" que nos es exigido. En este artículo pretendo enfocarme en un punto poco estudiado del Derecho Constitucional en general: los deberes constitucionales de la persona. Preliminarmente, consideramos a los deberes constitucionales como obligaciones jurídicas, exigibles y accionables. Esta visión que planteamos es radicalmente opuesta a la de la -poca- doctrina mayoritaria que los considera como simples obligaciones morales imposibles de hacer cumplir en el ámbito de la realidad.

Las personas tenemos derechos y eso es indiscutible (o por lo menos es bastante difícil de poner en duda). ¿Pero acaso no tenemos también deberes que cumplir frente al Estado y frente a las demás personas de la sociedad? Por otro lado, y si bien no es materia del presente trabajo, no podemos dejar de referirnos a los deberes del Estado, el cual no puede permanecer impávido frente a las diversas situaciones que se presentan en el ámbito de la realidad, como en el tema educativo. ¿Cómo exigirle al Estado que cumpla con sus deberes? ¿Debemos contentarnos con ver obligaciones en el papel, pero no en la práctica, resignándonos a que no exista un mecanismo efectivo para exigir su cumplimiento?

Relacionado con lo señalado anteriormente se abre un nuevo frente de batalla. En efecto, inclusive en el supuesto que logremos convencer a los lectores sobre la existencia y obligatoriedad de seguir los deberes constitucionales, se presenta un desafío mayor: ¿qué tipo de tutela jurisdiccional merecerían? Si el Derecho Procesal Constitucional tiene como uno de sus propósitos asegurar la vigencia y fuerza normativa de la Constitución, ¿también implica que debería asegurarse que se cumplan las disposiciones sobre deberes constitucionales? Si es así, ¿bajo qué proceso constitucional y bajo qué reglas procesales?

En este artículo no se podrá dar una respuesta a todas las interrogantes que surgen del tema. Se pretende introducir el tema al debate, rescatarlo del olvido en el que quedó y evaluarlo nuevamente. En efecto, creemos que tiene espacio para una amplia y fecunda aplicación en la realidad, mediante un desarrollo posterior y la contribución de otros trabajos sobre el asunto.

Por todo lo anteriormente mencionado, el problema al que pretendemos aproximarnos se puede condensar de la siguiente forma: si aceptamos que la Constitución tiene fuerza normativa y es jurídicamente vinculante por sí misma, contando además con procesos destinados a hacer que se cumplan y hagan efectivos ¿acaso no se deriva que los deberes recogidos en el texto constitucional los cuales enunciaremos más adelante- también gozan de las mismas características y de las mismas protecciones (o deberían hacerlo)? ¿Por qué, a lo largo de la historia y hasta la fecha, le hemos negado dichas características a los deberes constitucionales? En las siguientes líneas, se intentará dar una respuesta 
preliminar, introduciéndonos al tratamiento de los deberes constitucionales de la persona en el Perú.

\section{II. ¿Por qué hablar de deberes de la persona?: ¿Implica pasar por alto a los derechos?}

El Derecho es fruto de cada tiempo histórico: de lo bueno y de lo malo, de lo noble y sublime, de lo nefasto y lo sinestro. El momento que nos ha tocado vivir es sumamente complicado, pero son precisamente estas circunstancias las que nos deben llevar a reflexionar sobre los deberes que tenemos como personas en contextos particulares (ciudadanos de un Estado) y en uno global (ciudadanos del mundo). Probablemente se objete que no es correcto o posible plantear la exigencia de deberes si es que primero los derechos no son propiamente garantizados para todas y todos. Nos permitimos discrepar y adelantarnos a esta crítica.

Si bien es cierto que los derechos siguen padeciendo el problema de su poco reconocimiento y ejercicio en la práctica ("derechos de papel"), eso no impide discutir la exigencia de deberes. Los deberes han sido olvidados o subestimados por mucho tiempo y estimamos que es necesario ponerlos a debate. Efectivamente, los deberes constitucionales han sido poco estudiados por la doctrina nacional e internacional (e incluso cuando han sido estudiados, estos han merecido una escasa y superficial atención). En comparación con los textos y artículos que se han escrito sobre los derechos constitucionales, la cantidad de información académica e incluso jurisprudencial que existe sobre los deberes fundamentales es muy reducida.

Justo es anotar que el campo de los derechos constitucionales es más amplio y por lo tanto permite un mayor desarrollo teórico y práctico. Sin embargo, somos de la consideración que estamos avanzando paulatinamente hacia una sociedad en la que cada, cada vez con mayor intensidad y frecuencia, vamos reclamándole al Estado e incluso a los propios particulares el cumplimiento de "sus deberes", de "sus obligaciones", de lo que "tienen que cumplir". ¿Cuáles son esos deberes y por qué los tienen? ¿Qué nivel de exigibilidad tienen y por quién? ¿Pueden ser exigidos a nivel jurisdiccional?

En este contexto, las preguntas antes planteadas son problemáticas -pues exigen hacer que el Derecho, la Moral y la Política se concreten-, pero necesarias. En primer lugar, pues la comunidad científica suele coincidir unánimemente en que estamos avanzando hacia una sociedad con cada vez menos recursos (naturales y económicos, por poner algunos ejemplos) a disposición de las personas. Basta abrir un diario para darse cuenta que muchos de los conflictos sociales en nuestro país se generan por el fenómeno antes descrito. A modo de ejemplo, el agua, sea para consumo humano o actividades agrícolas, se está tornando en un recurso escaso que se ve amenazado, entre otras cosas, por el incumplimiento del deber constitucional de protección y conservación del ambiente. Algo tenemos que hacer, como sociedad, para enfrentar éste y otros problemas. No obstante, el "cómo" es lo que genera más discusiones. 
Efectivamente, nuestro modelo de Estado Social y Democrático de Derecho sigue reconociendo a la libertad individual como un principio de la más alta importancia. La autonomía de la persona es un elemento clave del constitucionalismo contemporáneo y abordar las esferas individuales suele generar mucha resistencia. Se considera que se trata de un "objetivismo ético", de abrir la puerta al "paternalismo jurídico" para la toma de decisiones de las personas e incluso al totalitarismo. Reconocemos las críticas que se pueden formular. No las ignoramos, pero creemos que son exageradas y le dan a la libertad un contenido vacío, libérrimo. No hay libertad sin responsabilidad. La individualidad de la persona no supone, pues, ignorar las responsabilidades y actuar de forma egoísta e ignorando a las demás personas de la comunidad, pues ello ya no implicaría individualidad, sino individualismo. Pensar en deberes constitucionales exige superar al individualismo: volver a pensar en la comunidad, y en nuestras obligaciones para con los demás.

\section{Estado de la cuestión: Breve mención a la doctrina y jurisprudencia nacionales e internacionales}

En el Perú, se presentó un trabajo al respecto1, elaborado por José Miguel Rojas Bernal, quien lo hizo con especial énfasis en los derechos económicos, sociales y culturales. Salvo por este artículo, no ha sido posible encontrar textos de autores nacionales en los que se hable, a profundidad, de los deberes constitucionales como tales ${ }^{2}$.

Las únicas dos excepciones a lo comentado anteriormente se encuentran en un breve trabajo preparado por Luis Durán Rojo, sobre el deber constitucional de contribuir, y en el artículo elaborado por el profesor español F. Javier Díaz Revorio, sobre los deberes constitucionales en la Constitución del Reino de España 4 .

En el caso de Durán Rojo, el trabajo versa principalmente sobre el deber

1 ROJAS BERNAL, José Miguel. "Los deberes constitucionales: elementos para una teoría general". En LEÓN FLORIÁN, Felipe Johan y José Miguel ROJAS BERNAL (Coordinadores). Derechos Humanos y constitucionalismo crítico. Ciudad de México: UBIJUS, 2015.

2 Un texto cuyo título es sugerente es el del ex Fiscal de la Nación, César Elejalde Estenssoro. Ver: ELEJALDE ESTENSSORO, César. Derechos y deberes fundamentales de la persona en la Constitución de 1979. Lima: Luis Combe Vélez Editores, 1990. Aunque es sin duda muy valioso, el libro no incluye una definición concreta sobre los deberes constitucionales ni muchos menos un análisis histórico de los mismos.

Luego de consultarse los textos clave de los profesores César Landa Arroyo ("Tribunal Constitucional y Estado Democrático"), Marcial Rubio Correa ("Estudio de la Constitución Política de 1993" - 06 Tomos) y Víctor García Toma ("Teoría del Estado y Derecho Constitucional"), se aprecia que no existe mayor información al respecto (y si la existe, como aquí se reseñará, es muy poca). Es decir, los grandes manuales de Derecho Constitucional en el Perú no se han ocupado, a profundidad, del tema.

3 DURÁN ROJO, Luis Alberto. "La noción del deber constitucional de contribuir. Un estudio introductorio". En DANÓS ORDOÑEZ, Jorge (Coordinador). Temas de Derecho Tributario y de Derecho Público. Libro Homenaje a Armando Zolezzi Möller. Lima: Palestra Editores, 2006, pp. 51-95. Algo similar, con relación a la parte tributaria, puede verse en: LANDA ARROYO, César. "La constitucionalización del Derecho peruano". En Revista Derecho PUCP, núm. 71, 2013, pp. 13-36.

4 DÍAZ REVORIO, F. Javier. "Sobre el concepto de deber constitucional y los deberes en la Constitución de 1978". En Pensamiento Constitucional, vol. 16, núm. 16, 2012, pp. 55-86. 
constitucional de contribuir, haciendo un breve recuento sobre lo que se considera como un deber constitucional. Consideramos que, pese a su enfoque, la reseña histórica que realiza sobre los deberes constitucionales es de suma utilidad para comprender su origen y naturaleza. Desde luego, es importante tomar en consideración que todo gira en torno al tema tributario, sin que haya un análisis constitucional ni de Teoría General del Derecho muy desarrollado.

En lo que respecta al texto del profesor F. Javier Díaz Revorio, su aporte está relacionado básicamente al contexto español, en el que los deberes constitucionales son más explícitos que en la Constitución peruana de 1993. Sin embargo, es importante destacar que, al iniciar su artículo, el autor comparte la misma apreciación sobre el asunto: no se ha escrito mucho (amplia y profundamente). Veamos:

"A diferencia de lo que sucede con los derechos, los deberes constitucionales no han sido en general objeto de un tratamiento doctrinal amplio y profundo. Aunque hay algún estudio o artículo muy estimable, no se puede decir que el concepto de deber constitucional y el análisis de los distintos deberes enunciados con tal condición en nuestra norma fundamental haya sido un objeto prioritario o fundamental para los estudiosos del Derecho Constitucional5". (énfasis añadido)

En cuanto a la jurisprudencia nacional, existe un voto singular del entonces Magistrado Gerardo Eto Cruz, el cual consta en la Sentencia del Tribunal Constitucional del Perú recaída en el Expediente $N^{\circ}$ 02111-2010-PA, de fecha 24 de enero de 2012. Veamos:

"47. Entre tanto, la idea de los deberes ha permanecido comúnmente postergada tanto en la doctrina así como en la práctica de los tribunales, pasando a ocupar un lugar marcadamente secundario en relación a la aludida prevalencia de los derechos. Aunado a ello, su simple entendimiento como razones para restringir derechos y libertades -o lo que es lo mismo, como necesario correlato de los mismos ("a todo derecho, un deber")-, ha ocasionado que los deberes constitucionales carezcan de una entidad propia pasible de ser exigida de manera autónoma con miras a resolver los casos concretos que se presentan en la realidad". (énfasis añadido)

Posteriormente, se pasó a desarrollar el deber de solidaridad y demás deberes de índole social, pues no solo el caso versaba sobre ello, sino que esa fue precisamente la tesis de quien colaboró con el entonces Magistrado en la elaboración de dicha sentencia ${ }^{6}$. Fuera de ese caso, no se ha encontrado mención ni desarrollo en otros expedientes que probablemente lo ameritaban, como es el caso del servicio militar

5 DÍAZ REVORIO, F. Javier. "Sobre el concepto de deber constitucional y los deberes en la Constitución de 1978". En Pensamiento Constitucional, vol. 16, núm. 16, 2012, p. 56.

6 José Miguel Rojas Bernal fue practicante del Gerardo Eto Cruz y, ya como abogado, laboró con él en su propio Estudio. 
obligatorio ${ }^{7}$. En este último caso, pese a que la demanda tenía, en el fondo, sustento en el deber de proteger los intereses nacionales (artículo $38^{\circ}$ de la Constitución) mediante la participación en la defensa nacional, el Tribunal Constitucional no se pronunció sobre el tratamiento los deberes constitucionales de la persona en el Perú. Así las cosas, en el caso de la jurisprudencia nacional, el tema de los deberes constitucionales se ha desarrollado únicamente vía un voto singular.

A nivel internacional, el panorama es similar al peruano. Por ejemplo, en el caso de la Corte Constitucional de Colombia -referente, junto con el Tribunal Constitucional del Reino de España, para el Tribunal Constitucional del Perú-, dicha alta corte se ha pronunciado en pocas ocasiones. Sobre ello volveremos más adelante.

Siendo éste el "estado de la cuestión" en materia de deberes constitucionales de la persona, en las siguientes líneas nos enfocaremos en un planteamiento teórico, desarrollando conceptos y presentando algunas ideas generales e introductorias sobre el tratamiento los deberes constitucionales de las personas en el Perú.

\section{Sobre la noción del término "deber": Conceptos previos para el tratamiento de los deberes constitucionales}

\section{i. ¿Qué entendemos por deber?}

Las personas tenemos responsabilidades, cargas y/o compromisos que asumir, pues corresponde que así lo hagamos. Existe un sentido de obligación, de saber que tenemos que hacer algo, que es imperioso y de obligatorio cumplimiento. A ello llamamos "deber". La palabra "deber", según una de las acepciones del Diccionario de la lengua española, es estar "obligado a algo por la ley divina, natural o positiva8" y desde la perspectiva del Derecho es una "situación jurídica constituida por la exigencia de observar una determinada conducta" ${ }^{91}$.

\section{ii. Deberes morales, sociales y jurídicos: Los deberes como situaciones jurídicas de desventaja}

Como toda conducta, un deber puede ser, entre otras cosas: (i) moral; (ii) social; o, (iii) jurídico. En el caso del deber moral, creemos o consideramos que debemos hacer algo, pues de lo contrario nos sentiremos mal (nuestra conciencia nos atormentará) o seremos reprimidos espiritualmente (en el caso religioso, por ejemplo). En el segundo caso, el deber social viene impuesto por nuestra comunidad o nuestro círculo íntimo, el cual puede "sancionarnos" por su incumplimiento (aislándonos o cortando vínculos, por poner un ejemplo). Por supuesto, no tendrá ningún respaldo coercitivo del Estado (digamos, que un juez

7 Sentencia del Tribunal Constitucional del Perú recaída en el Expediente Nº00015-2013-PI, de fecha 23 de mayo de 2014.

8 Consulta realizada el 27 de setiembre de 2020. Disponible en: https:// dle.rae.es/deber\#Bu2rLyz

9 COUTURE, Eduardo J. Vocabulario Jurídico. Español y latín, con traducción de vocablos al francés, italiano, portugués, inglés y alemán. Buenos Aires: Depalma, 1976, p. 198. 
nos condene por ello), pues no ha sido recogido en alguna norma positiva (plano jurídico).

En el último caso, los deberes jurídicos imponen una obligación, carga o compromiso, implicando así una situación jurídica de desventaja (la persona "A" debo hacer algo a favor de la persona "B" o la comunidad en general). Recordemos que, desde la Teoría General del Derecho, podemos distinguir entre las situaciones jurídicas de ventaja y las situaciones jurídicas de desventaja. Según la doctrina, la distinción entre una y otra está fácilmente orientada al interés protegido. Así, serán:

"situaciones subjetivas de ventaja las situaciones atribuidas al sujeto en su interés (seguidamente de la calificación d su interés) y son situaciones subjetivas de desventaja las situaciones impuestas a un sujeto por un interés ajeno (seguidamente de la calificación con el fin de garantizar un interés ajeno) $[\ldots]$

La situación de ventaja es apta para asegurar al titular la obtención de un resultado favorable (satisfacción de un interés por medio de la consecución de una utilidad). La situación de desventaja sirve de instrumento para la realización de la primera y se determina en función de ella $[\ldots]^{10 "}$.

Así entendidas las cosas, un deber es distinto a un derecho, pues un derecho implica la facultad o potestad que tienen las personas para poder desenvolverse y alcanzar un determinado grado de satisfacción (situación jurídica de ventaja). Mientras que a la persona que es titular de un derecho le corresponde la posibilidad de ejercer esa situación jurídica a su favor (podría decidir no hacerlo), al titular de un deber le corresponde cumplir con el mandato que tiene (incluso si no quisiera hacerlo).

Sin embargo, que sean distintos no significa que no tengan ninguna relación, pues, en principio, todo derecho implica, necesariamente, un deber como contrapartida: a toda situación jurídica de ventaja le corresponde una situación jurídica de desventaja. Si una persona tiene un derecho, nos corresponde a los demás el deber de, cuando menos, respetarlos y garantizarlos.

Por tanto, y en línea de principio, siguiendo lo señalado por el profesor García Belaunde, podemos señalar que los deberes son la contrapartida de los derechos ${ }^{11}$. Son, por decirlo de algún modo, dos caras de una misma moneda. Sin embargo, justo es anotar que pueden existir deberes (situaciones jurídicas de desventaja) que

10 MORALES HERVIAS, Rómulo. "La propiedad en las situaciones jurídicas subjetivas". En PRIORI POSADA, Giovanni F. (Editor). Estudios sobre la propiedad. Lima: Fondo Editorial de la Pontificia Universidad Católica del Perú, 2012, p. 97.

11 GARCÍA BELAUNDE, Domingo. La Constitución y su dinámica. Segunda edición. Lima: Palestra Editores, 2006, p. 266. 
no tengan como correlato sus respectivos derechos (situaciones jurídicas de ventaja) $)^{12}$.

\section{Deberes constitucionales en el Perú: Introducción a su tratamiento}

\section{i. ¿Deberes humanos, deberes fundamentales o deberes constitucionales?}

En el Perú, es pacífico emplear los términos "derechos humanos", "derechos constitucionales" o "derechos fundamentales" como sinónimos y de forma indistinta ${ }^{13}$. A fin de cuentas, todos buscan transmitir la misma idea: "la constitucionalización de una serie de exigencias humanas que, formuladas como bienes humanos, son debidos a la persona por ser tal14".

En consecuencia, no parece haber problema en lo que respecta a derechos constitucionales, pues, independientemente del nombre que les demos o del origen de los mismos, importan un mayor beneficio para la persona. Lo importante, así, es brindarle al ser humano la gama más amplia de protecciones, en tanto todo derecho es una situación jurídica de ventaja. Como lo favorece, no hay problema en incorporar su contenido a la esfera individual de cada persona.

Sin embargo, cuando nos referimos a los deberes, la situación cambia. Y cambia, realmente, de forma muy importante, pues sí es vital atender a la fuente de donde provienen y a las posibilidades de su exigencia. Como indicamos previamente, un deber es una situación jurídica de desventaja: una obligación o carga que tenemos las personas, en virtud de alguna disposición o mandato. En este caso, por "deber constitucional" deberíamos entender a aquella obligación o carga para los particulares ${ }^{15}$ que deriva expresamente de una norma constitucional recogida por

12 Esto es importante pues, si asumimos que los deberes sólo pueden existir en tanto existan los derechos, no podrían existir deberes para cumplir fines constitucionalmente valiosos y legítimos por sí mismos. Preliminarmente, consideramos que, si bien a todo derecho le corresponde un deber (como el de respetar el derecho en cuestión, pero también otros), sí es posible que existan deberes "independientemente" de derechos.

Sobre eso se profundizará a detalle en un trabajo posterior, sin perjuicio de dejar constancia de que nuestra posición -pueden existir deberes sin que exista de correlato un derecho- se sustenta en lo señalado por el profesor español Gregorio Peces-Barba (en palabras del profesor peruano Reynaldo Bustamante Alarcón) al abordar el valor constitucional de la solidaridad, afirmando que es posible "construir, a partir de él, una serie de obligaciones jurídicas sin que necesariamente tengan que existir los derechos correlativos, como las referidas a los intereses de las generaciones futuras". BUSTAMANTE ALARCÓN, Reynaldo. La idea de persona y dignidad humana. Madrid: Editorial Dykinson, 2018, p. 271.

13 Poco importa que: (i) los primeros estén referidos a derechos consagrados en normas positivas internacionales - tratados o convenciones- y con la vocación de ser aplicables a todas las personas con prescindencia de su ubicación geográfica o temporal (la persona en general); (ii) los segundos estén referidos a aquellos consagrados en la norma suprema positiva nacional de cada Estado (Constitución) (Ver: CASTILLO CÓRDOVA, Luis. "Acerca de la constitucionalidad material de las causales que habilitan el rechazo sin más trámite del recurso de agravio constitucional". En GRÁNDEZ CASTRO, Pedro P. (Coordinador). El debate en torno a los límites al recurso de agravio constitucional. Cuadernos sobre Jurisprudencia Constitucional $\mathrm{N}^{\circ}$ 09. Lima: Palestra Editores, 2014, p. 78): o, (iii) los últimos sean -en determinados ordenamientos como el alemán o el español- una serie de derechos especiales dentro del mismo texto constitucional, con una protección reforzada distinta a la de los demás derechos recogidos en dicho cuerpo normativo

14 CASTILLO CÓRDOVA, Luis. "El contenido constitucional de los derechos fundamentales". Madrid: Anuario Iberoamericano de Justicia Constitucional. Número 14, 2010, p. 93.

$15 \mathrm{Y}$, eventualmente, para el Estado. No obstante, escapa a los alcances de esta introducción. 
la Constitución peruana16. Así, en palabras de la Corte Constitucional de Colombia, los deberes constitucionales son "aquellas conductas o comportamientos de carácter público, exigibles por la ley a la persona o al ciudadano, que imponen prestaciones físicas o económicas y que afectan, en consecuencia, la esfera de su libertad personal17". La fuente de los deberes debe provenir de cada Constitución en particular.

Con ello, estamos obviando referirnos a "deberes humanos", aplicables a todas las personas por el solo hecho de serlo o a "deberes fundamentales" como obligaciones o cargas especiales dentro de un texto constitucional, con una mayor fuerza que otros deberes constitucionales.

Carl Schmitt, de forma consecuente con su modo de ver las cosas en el Derecho Constitucional, consideró que no era posible hablar de "deberes fundamentales". A su criterio:

"[1]os deberes fundamentales no son deberes del hombre en general, sino sólo deberes del miembro o del sometido al Estado, es decir, de los hombres que se encuentran dentro de la esfera de poder del Estado. [...] Sólo pueden ser, entonces, deberes en un sentido jurídico positivo, resultando limitados. Deberes ilimitados en principio contradirían también la idea del Estado burgués de Derecho. Por eso, todo deber existe sólo «a medida de las leyes», que delimitan el supuesto y contenido del deber ${ }^{18 " .}$ (énfasis añadido)

Coincidimos parcialmente con Schmitt en este planteamiento, pues es extremadamente difícil -si es que no imposible- referirnos a: (i) obligaciones o cargas a las que deban ser sometidas todas las personas en general (aunque puede haber mínimos universalmente exigibles); o, (ii) cargas u obligaciones especiales de una mayor jerarquía que otras recogidas en una Constitución. Es mejor referirnos, de ahora en adelante, a los "deberes constitucionales".

\section{ii. Sustento de los deberes constitucionales: La solidaridad}

Como señala el profesor Reynaldo Bustamante, la natural vocación comunitaria de la persona nos lleva a propugnar el valor de la solidaridad, por cuanto éste "representa la cooperación de todos en el pleno desarrollo de los demás, el progreso de la comunidad y el cuidado de la naturaleza ${ }^{19}$ ". La solidaridad es un importante criterio para cohesionar a la comunidad, pero también para orientar a

16 "Cuando un deber jurídico nace con cargo a ser cumplido por una persona, ésta pierde la prerrogativa de omitir lo que se le impone y de hacer lo que se le prohíbe: el obligado no es jurídicamente autónomo. Es decir, cuando se ordena una acción, el deber jurídico es fundante del derecho de ejecutar la conducta obligatoria; cuando se la prohíbe, el deber jurídico es fundante del derecho de omitir la conducta ilegal" (énfasis añadido). GARCÍA TOMA, Víctor. Teoría del Estado y Derecho Constitucional. Cuarta edición. Lima: Adrus D\&L Editores, 2014, p. 726.

17 Sentencia $N^{\circ}$ T-125/94 del 14 de marzo de 1994, recaída en el Expediente $N^{\circ} \mathrm{T}-23703$. Numeral 3 de los Fundamentos Jurídicos.

18 SCHMITT, Carl. Teoría de la Constitución. Madrid: Alianza Editorial, 2011, p. 236.

19 BUSTAMANTE ALARCÓN, Reynaldo. La idea de persona y dignidad humana. Madrid: Editorial Dykinson, 2018, p. 269. 
la producción, interpretación y aplicación del ordenamiento jurídico en un Estado Social y Democrático de Derecho. El punto de partida de la solidaridad "es el reconocimiento de la realidad del otro y la consideración de sus problemas como no ajenos, sino susceptibles de resolución con intervención de los poderes públicos y de los demás20". Y es que:

"La solidaridad contribuye igualmente a la creación de cauces de comunicación en la sociedad, que permite un diálogo ilustrado entre personas que se respetan y se reconocen, y que contribuyen en ese esquema compartido a poner en común, a discutir y a formar criterios morales que superan la pura individualidad. La solidaridad refuerza así la idea de que un proyecto moral debe poder ser elevado a ley general, puesto que es construido comunitariamente ${ }^{21 "}$.

La solidaridad, además, promueve el ejercicio de los derechos de forma respetuosa con los demás. Asimismo, "evita una afirmación tajante y absoluta del propio derecho y tiene en cuenta los perjuicios que se pueden producir a terceros. En definitiva, intenta incorporar la doctrina del abuso del Derecho al tema de los derechos fundamentales 22". No obstante, también sirve de sustento para los deberes constitucionales, pues no sólo se expresa en derechos, sino "también en obligaciones positivas (de dar y de hacer) a cargo de los poderes públicos y especialmente- de los particulares 23 ". En consecuencia, el sustento de los deberes constitucionales el valor jurídico de la solidaridad.

\section{iii. Objetivo de los deberes constitucionales de la persona}

¿Y para qué sirven los deberes constitucionales? Siguiendo a Durán Rojo, podemos coincidir en que, en un Estado Constitucional que sigue el modelo del Estado Social y Democrático de Derecho, los deberes constitucionales se presentan para promover la realización de determinados fines que recoge la Constitución, permitiendo el establecimiento de determinadas herramientas que son requeridas para alcanzar dichos fines24. Así, son cargas necesarias para asegurar la vida en común que desarrollamos en la sociedad. Ese es su propósito y razón de ser.

Un deber constitucional, en esos términos, era inconcebible en un Estado Liberal en el que se privilegiaba la libertad individual por encima de todo. Sin embargo, ello ha cambiado bajo el modelo del Estado Social y Democrático de Derecho, pues no se busca -únicamente- limitar y controlar al Estado y a la sociedad. También se busca "promover y crear las condiciones jurídicas, políticas, sociales, económicas

20 PECES-BARBA MARTÍNEZ, Gregorio. Curso de Derechos Fundamentales. Teoría General. Madrid: Universidad Carlos III de Madrid y Boletín Oficial del Estado, 2014, p. 280.

21 Ídem.

22 PECES-BARBA MARTÍNEZ, Gregorio. Curso de Derechos Fundamentales. Teoría General. Madrid: Universidad Carlos III de Madrid y Boletín Oficial del Estado, 2014, p. 282.

23 BUSTAMANTE ALARCÓN, Reynaldo. La idea de persona y dignidad humana. Madrid: Editorial Dykinson, 2018, p. 269.

24 DURÁN ROJO, Luis Alberto. "La noción del deber constitucional de contribuir. Un estudio introductorio". En DANÓS ORDOÑEZ, Jorge (Coordinador). Temas de Derecho Tributario y de Derecho Público. Libro Homenaje a Armando Zolezzi Möller. Lima: Palestra Editores, 2006, p. 60. 
y culturales que permitan el máximo desarrollo de la persona, con absoluto respeto a su dignidad $[\ldots]^{25 "}$. En este modelo de Estado, la libertad también es defendida, pero no es entendida simplemente como la facultad de hacer todo aquello que no está prohibido, sino que además se le otorgan funciones de carácter social26: cargas, deberes u obligaciones para con los demás y el Estado, a fin de realizar el bien común.

\section{iv. Los deberes constitucionales expresamente consagrados en la Constitución peruana de 1993: Un catálogo corto e imperfecto}

¿Cuáles son los deberes constitucionales en el Perú? Además de los enunciados en algunos tratados internacionales clave27, pocos son nominados expresamente: (i) deber de los vecinos de participar en el gobierno municipal de su jurisdicción

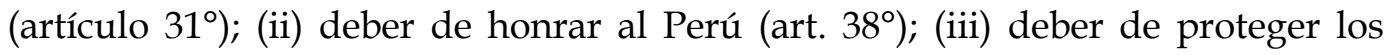

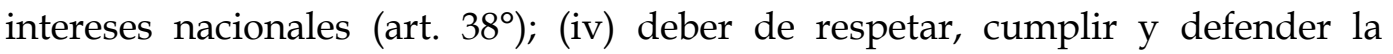
Constitución y el ordenamiento jurídico de la Nación (art. 38 $)$; (v) deber de contribuir a la promoción y defensa de la salud individual, la del medio familiar y de la comunidad $\left(\operatorname{art.} 6^{\circ}\right) ; \mathrm{y}$, (vi) el deber de trabajar $\left(\operatorname{art.} 22^{\circ}\right)^{28}$.

25 LANDA ARROYO, César. "El derecho del trabajo en el Perú y su proceso de constitucionalización: Análisis especial del caso de la mujer y la madre trabajadora". En THËMISRevista de Derecho, núm. 65, 2014, p. 220.

26 Sentencia del Tribunal Constitucional 0008-2003-AI del 11 de noviembre de 2003. Fundamento jurídico 12

27 Me refiero a la Declaración Universal de Derechos Humanos y a la Convención Americana sobre Derechos Humanos.

Declaración Universal de Derechos Humanos

"Artículo 29.

1. Toda persona tiene deberes respecto a la comunidad, puesto que sólo en ella puede desarrollar libre y plenamente su personalidad. [...]".

Convención Americana sobre Derechos Humanos.

"Artículo 32. Correlación entre Deberes y Derechos

1. Toda persona tiene deberes para con la familia, la comunidad y la humanidad.

2. Los derechos de cada persona están limitados por los derechos de los demás, por la seguridad de todos y por las justas exigencias del bien común, en una sociedad democrática".

Adicionalmente, en la Declaración de los Derechos del Hombre y del Ciudadano (1789), el Preámbulo indica que uno de sus objetivos es que se "les recuerde sin cesar sus derechos y sus deberes" a las personas. Así también, en el Preámbulo de la Declaración Americana de los Derechos y Deberes del Hombre (1948), se indica que: "El cumplimiento del deber de cada uno es exigencia del derecho de todos. Derechos y deberes se integran correlativamente en toda actividad social y política del hombre. Si los derechos exaltan la libertad individual, los deberes expresan la dignidad de esa libertad.

Los deberes de orden jurídico presuponen otros, de orden moral, que los apoyan conceptualmente y los fundamentan.

Es deber del hombre servir al espíritu con todas sus potencias y recursos porque el espíritu es la finalidad suprema de la existencia humana y su máxima categoría.

Es deber del hombre ejercer, mantener y estimular por todos los medios a su alcance la cultura, porque la cultura es la máxima expresión social e histórica del espíritu.

Y puesto que la moral y buenas maneras constituyen la floración más noble de la cultura, es deber de todo hombre acatarlas siempre". Todo el Capítulo Segundo de esta Declaración (artículos $29^{\circ}$ a $38^{\circ}$ contiene deberes).

28 Blancas Bustamante, refiriéndose al deber de trabajar que consagra el artículo $22^{\circ}$ de nuestra Constitución, ha señalado que "es una obligación en sentido social o moral, pero de ningún modo en sentido jurídico, en la medida en que no existen mecanismos que obliguen a las personas a trabajar y las sancionen por no hacerlo". En efecto, no existen mecanismos coercitivos anudados al mismo que permitan exigirle a los particulares el cumplimiento de este deber constitucional. 
Existen otros propios referidos a la educación o a las relaciones familiares, pero no parecen ser aplicables de modo general a toda persona ${ }^{29}$. Así las cosas, y en comparación con el catálogo de derechos constitucionales de las personas, lo regulado en el Perú para los deberes es minúsculo y casi inexistente. Creemos que ello genera un serio problema: si resolvemos todo en clave de derechos, nadie internaliza las consecuencias de sus acciones y las responsabilidades que pueden traer los derechos. Es decir, se deja el debate en una lógica -creemoslibertaria de obtener beneficios individualmente sin límites, responsabilidades o consecuencias por su ejercicio abusivo o irracional, ni mucho menos pensando en la comunidad.

Esta forma de ver el mundo ha moldeado las circunstancias por las que atravesamos: una genuina crisis climática que pone en riesgo el planeta como lo conocemos y amenaza la vida de muchas especies (incluida la humana); un modelo de capitalismo exacerbado y deshumanizante que se sostiene en estructuras y figuras injustas (como la explotación de las personas y los paraísos fiscales), cuando este modelo (capitalismo) podría (tiene que) ser más humano; y un individualismo hedonista que le rehúye a las responsabilidades. Coincidimos con autorizada doctrina nacional cuando señala que el ser humano no es solipsista (no puede encerrarse en sí mismo), sino que "debe ser un actor social que participa activamente en la sociedad, que coopera con el progreso de su comunidad y con el desarrollo de quienes como él son personas. La comunidad, por su parte, no debe preocuparse solamente de su progreso colectivo, sino constituirse en un ambiente propicio para que cada persona, con su esfuerzo, pero con el apoyo de los demás, pueda alcanzar su pleno desarrollo30". El valor jurídico de la solidaridad, y, por extensión, la defensa de los deberes constitucionales de la persona, exige apuntar

Ver: BLANCAS BUSTAMANTE, Carlos. La cláusula del Estado social en la Constitución. Análisis de los derechos fundamentales laborales. Lima: Fondo Editorial de la Pontificia Universidad Católica del Perú, 2011, p. 349.

En palabras del profesor Toyama: "El deber de trabajo descrito en el artículo 22 de la Constitución viene a ser como una obligación general a los ciudadanos sin una sanción concreta, es una suerte de «llamada a la participación en el interés general [...], de lo que se trata es de vincular este deber al principio de solidaridad social»". TOYAMA MIYAGUSUKU, Jorge. Derechos laborales ante empleadores ideológicos. Derechos fundamentales e ideario empresarial. Lima: Fondo Editorial de la Pontificia Universidad Católica del Perú, 2012, p. 60.

Una posición particular parece ser la del profesor García Toma, pues, si bien reconoce que es una obligación (moral), no identifica cuál es la consecuencia de su incumplimiento: "[...] se considera que toda persona tiene la exigencia moral de desarrollarse como tal a través del trabajo; amén de obtener los recursos para vivir por sí mismo, acorde con las capacidades y habilidades que posee y dentro de las circunstancias que lo circundan. [...] En ese aspecto, el ser humano [...] carece de libre e irrestricta disposición o señorío sobre el uso o no uso de sus capacidades y habilidades laborales, ya que estas guardan relación axiológica con las responsabilidades que le incumben, en torno al interés general de la sociedad en donde mora y se realiza". GARCÍA TOMA, Víctor. Los derechos fundamentales. Segunda edición. Arequipa: Editorial Adrus, 2013, pp. 672-673.

29 Existe, además, un deber innominado que se deriva del artículo $74^{\circ}$ de la Constitución, ampliamente conocido como deber de contribuir, relacionado estrechamente con el principio de solidaridad. Ver: DURÁN ROJO, Luis Alberto. "La noción del deber constitucional de contribuir. Un estudio introductorio". En DANÓS ORDOÑEZ, Jorge (Coordinador). Temas de Derecho Tributario y de Derecho Público. Libro Homenaje a Armando Zolezzi Möller. Lima: Palestra Editores, 2006, p. 91.

30 BUSTAMANTE ALARCÓN, Reynaldo. La idea de persona y dignidad humana. Madrid: Editorial Dykinson, 2018, p. 171. 
al bien común y rechazar al individualismo, es decir, a "la irresponsabilidad, el desinterés que prescinde de los demás y de la propia comunidad"31. El individualismo, en efecto:

"acoge el hábito de analizar los problemas humanos desde los deseos caprichosos del individuo y no desde el punto de vista del bien de la comunidad; olvida la importancia de la sociedad en el desarrollo integral de la persona y exalta la libertad de elección del individuo hasta prescindir de todo referente ético $[\ldots]^{32 "}$.

Se aprecia, en consecuencia, cómo es que los deberes constitucionales de la persona no son compatibles con el individualismo.

La falta de deberes fundamentales (verdaderas obligaciones jurídicas) lleva también a que las limitaciones a derechos fundamentales sean poco toleradas. Nos explicamos: si no se interioriza que, así como tenemos derechos, tenemos deberes, nuestra impresión es que por más válidas que sean las restricciones, éstas serán más propicias a ser incumplidas. Por ejemplo, durante el Estado de Emergencia Nacional y la Emergencia Sanitaria en Perú por la pandemia del COVID-19, en los que se requiere que la gente evite las aglomeraciones y salir de su casa si no es genuinamente indispensable, para incumplir las restricciones han sido bastante frecuentes las respuestas invocando derechos ("quiero reunirme con mi familia y amigos") bajo la lógica de que solo lo afecta a uno ("y si me enfermo, que así sea"). ¿Y qué hay de los deberes individuales, de nuestra responsabilidad en que los demás gocen de sus derechos?

Es necesario que todos interioricemos que, así como tenemos derechos, tenemos deberes, pues muchos de los problemas que se presentan en nuestra sociedad se derivan del desconocimiento que tenemos obligaciones para poder convivir adecuadamente en sociedad, en comunidad. Hacemos nuestras las consideraciones del profesor Rubio Correa cuando señala lo siguiente:

"Consideramos que establecer no sólo los derechos sino también los deberes de las personas frente a la sociedad es una labor normativa importante porque educa al ciudadano en el respeto a la sociedad de la que tiene derechos y lo acostumbra a ver no sólo beneficios sino también cargas y responsabilidades ${ }^{33 "}$. (énfasis añadido)

VI. El incumplimiento de los deberes y los mecanismos para exigir que se respeten

i. ¿Hay sanciones por incumplir un deber constitucional en el Perú?

31 BUSTAMANTE ALARCÓN, Reynaldo. La idea de persona y dignidad humana. Madrid: Editorial Dykinson, 2018, p. 180.

32 BUSTAMANTE ALARCÓN, Reynaldo. La idea de persona y dignidad humana. Madrid: Editorial Dykinson, 2018, p. 181.

33 RUBIO CORREA, Marcial. Estudio de la Constitución Política de 1993. Tomo II. Lima: Fondo Editorial de la Pontificia Universidad Católica del Perú, 1999, p. 410. 
Basta revisar la Constitución Política de 1993 para comprobar que no se ha previsto ninguna sanción por incumplir con los deberes constitucionalmente enunciados. Es más, tampoco se ha previsto algún mecanismo por medio del cual se pueda compeler o requerir a una persona para que cumpla con su deber constitucional. Teóricamente, ello no debería suponer un obstáculo, pues como señala el profesor García Toma, si advertimos que un deber constitucional ha sido -o está siendoincumplido, lo primero que debe hacerse es compeler a la persona a, valga la redundancia, cumplirlo. En otras palabras, frente a un deber incumplido, es imprescindible exigir que se cumpla ${ }^{34}$.

Por ejemplo, en el Perú tenemos el caso del recientemente reconocido derecho al agua. Conforme a éste, las personas tenemos derecho de acceder al agua. ¿Pero acaso ello no conlleva a una responsabilidad en su uso? Hasta hace muy poco en la ciudad de Lima era frecuente el derroche de agua en los llamados "carnavales" (febrero), tirando globos, bateas y baldes cargados de agua con el único propósito de "divertirse". Esta actividad es cada vez más reprochable socialmente, ante las circunstancias de la ciudad y del mundo: el agua se está convirtiendo en un recurso escaso por la acción (e inacción) de la humanidad, por lo que utilizarla en estos carnavales no solo es un desperdicio, sino que afecta a la colectividad. Sin embargo, la práctica continúa. ¿Qué hacer al respecto? Quizá en el camino pueda determinarse alguna sanción (pecuniaria, por ejemplo), por incumplir el deber de preservar el agua; es decir, por impedir que la comunidad presente y futura pueda gozar de dicho recurso.

El propósito del ejemplo brindado en el párrafo anterior es evidenciar que sin sanciones efectivas (consecuencias concretas por incumplir un deber), las obligaciones de índole constitucional se verán claramente disminuidas en su efectividad, pues incumplirlas no acarrearía ninguna situación gravosa para la persona que los ignora. Es necesario incluir mecanismos de coerción para exigir que un deber sea respetado.

Ahora bien, el problema, por supuesto, no es sólo teórico, sino práctico. Y es que, como veremos en el siguiente acápite, un proceso constitucional debería poder servir para exigir el cumplimiento de un derecho (aunque a la fecha ello no sea posible).

\section{ii. ¿La jurisdicción constitucional puede ser un medio para la exigencia de los deberes constitucionales?}

¿Cómo hacer que se cumpla un deber constitucional? ¿Existen mecanismos procesales para lograr que se materialicen? Actualmente no existen, por falta de previsión a nivel constitucional y de desarrollo legislativo. Sin embargo, teóricamente, es posible construirlo a partir de ciertas premisas. Como se señaló anteriormente, los deberes constitucionales cobran especial importancia en un Estado Social y Democrático de Derecho, pues apuntan a hacer más fácil y viable

34 GARCÍA TOMA, Víctor. Teoría del Estado y Derecho Constitucional. Cuarta edición. Lima: Adrus D\&L Editores, 2014, p. 726. 
la vida en común. Es recordarle a la persona que no sólo tiene derechos, sino deberes, entendidos como cargas, obligaciones y/o compromisos.

Dichos deberes deben venir del texto constitucional, el cual en un Estado Social y Democrático de Derecho, tiene fuerza normativa, en tanto la Constitución es: (i) lex legis -ley de leyes-, dado que se encuentra en el vértice de las demás normas y prima en caso de conflicto sobre ellas; y, (ii) norma normarum -norma fuente de normas-, pues constituye la norma matriz para la creación de las demás normas del sistema jurídico ${ }^{35}$.

Ello quiere decir que todo cuanto ella contiene es jurídicamente exigible y vinculante para todos los poderes públicos y privados, incluyendo a los deberes constitucionales que consagra. Sin embargo, de nada servirían estas características si es que no pudieran ser puestas en práctica, si es que no pudieran ser exigibles.

A fin de conseguir que se cumpla lo señalado en la Constitución, aparece la jurisdicción constitucional, como aquel "conjunto de normas, órganos y procesos normalmente de naturaleza judicial- que definen el contenido y ejecución de la función de controlar que la Constitución tenga plena vigencia en la realidad 36 ". Su propósito, como ya se ha señalado, es "hacer realidad la finalidad de la Constitución: limitar el poder, ya sea este de naturaleza pública o de naturaleza privada $^{37 " .}$

Para ello, la jurisdicción constitucional se sirve de procesos constitucionales, los cuales son herramientas judiciales que están destinadas a mantener la vigencia de la Constitución. Existen dos grandes tipos de procesos constitucionales: (i) de tutela de derechos por afectación a la faz subjetiva (incluyendo al amparo, al hábeas corpus, al hábeas data y al proceso de cumplimiento), también llamados como "procesos de la libertad 38 "; y, (ii) de control normativo por afectación a la faz objetiva (inconstitucionalidad y acción popular). El proceso competencial no calza propiamente en ninguno de los dos grupos.

Si somos acuciosos, advertiremos que ninguno de esos procesos está pensando para buscar el cumplimiento de un deber (situación jurídica de desventaja). Todo lo contrario, están previstos para tutelar y proteger derechos (situaciones jurídicas de ventaja). El único proceso que podría calzar, en caso se reforme la Constitución y se modifique la legislación pertinente ${ }^{39}$, es el proceso de cumplimiento, el cual busca "asegurar la eficacia de las normas legales y los actos administrativos $40 "$,

35 Visto en: LANDA ARROYO, César. "La constitucionalización del Derecho Civil: El derecho fundamental a la libertad contractual, sus alcances y sus límites". En THĒMIS-Revista de Derecho, núm. 66, 2014, p. 312.

36 CASTILLO CÓRDOVA, Luis. El Tribunal Constitucional peruano y su dinámica jurisprudencial. Lima: Palestra Editores, 2008, p. 41.

37 Ídem.

38 CAPPELLETTI, Mauro. La jurisdicción constitucional de la libertad. Con referencia a los ordenamientos alemán, suizo y austriaco. Lima: Palestra Editores e Instituto de Derecho Comparado de la Universidad Nacional Autónoma de México, 2010.

39 Nos referimos, evidentemente, al Código Procesal Constitucional.

40 LANDA ARROYO, César. Tribunal Constitucional y Estado Democrático. Lima: Fondo Editorial de la Pontificia Universidad Católica del Perú. 1999. p. 172. 
convirtiendo su cumplimiento en un derecho fundamental de las personas ${ }^{41}$. Busca, en estricto, que algo se cumpla. El problema es que no está pensando para hacer que sea la Constitución misma la que se cumpla.

Irónico, por decirlo menos, que la Constitución regule un proceso constitucional específicamente para el cumplimiento de cuestiones infra-constitucionales (como las normas legales y los actos administrativos), dejando sin protección el acatamiento de sus propias cargas y/o mandatos, conocidos como deberes constitucionales. Esto debería ser materia de una reforma constitucional para poder exigir jurídicamente el pleno cumplimiento de los deberes pues, como ha señalado la Corte Constitucional de Colombia, es necesario una habilitación constitucional para que el legislador desarrolle y concrete en qué consiste el deber y posibles sanciones por su incumplimiento:

"Las restricciones a la libertad general sólo pueden estar motivadas por fundadas razones que determine el Legislador. En este sentido, los deberes consagrados en la Constitución comprenden una habilitación al Legislador para desarrollar y concretar la sanción por el incumplimiento de los parámetros básicos de conducta social fijados por el Constituyente42".

\section{Conclusiones y análisis futuro: El estudio de los deberes constitucionales recién empieza}

Preliminarmente se puede concluir que, así como existen derechos, existen deberes. No siempre habrá la correlación derecho-deber, aunque sin duda es un punto de partida importante. No son solo exigencias morales o sociales, sino jurídicas: son situaciones jurídicas de desventaja y, por consiguiente, en teoría, se puede exigir su cumplimiento forzoso mediante medios coercitivos. Son de obligatorio cumplimiento.

En el caso peruano, la Constitución consagra pocos deberes (la mayoría nominados), siendo que el catálogo de derecho es mucho más extenso en comparación con el de las obligaciones constitucionalmente exigibles. Además, como se desarrolló, nuestra Constitución no plantea sanciones específicas en caso de incumplimiento, lo cual le resta efectividad a la exigencia de los deberes. Asimismo, tampoco prevé mecanismos jurisdiccionales para demandar que un deber sea satisfecho. Si bien en teoría es posible pensar en que un proceso constitucional sirva para compeler a una persona a cumplir con su deber, lo cierto es que, a la fecha, ni la Constitución de 1993 ni el Código Procesal Constitucional consagran mecanismos efectivos para el cumplimiento de los deberes.

Su tratamiento deficiente es un problema, pero también una oportunidad. No solo para profundizar en el estudio de los deberes constitucionales -éste ha sido sólo un análisis introductorio sobre su tratamiento en el caso peruano- $y$

41 Ídem.

42 Sentencia $N^{\circ}$ T-125/94 del 14 de marzo de 1994, recaída en el Expediente Nº T-23703. Numeral 3 de los Fundamentos Jurídicos. 
eventualmente plantear una reforma a la Constitución de 1993, para incluir normas más concretas, tanto en materia de sanciones, como en mecanismos para exigir su cumplimiento, lo cual corresponderá ser desarrollado y complementado razonablemente por el legislador democrático.

No obstante, el trabajo recién empieza. Quedan muchas dudas y preguntas por resolver, pero el solo hecho de introducir el tema al debate para "desempolvar" a los deberes del olvido constitucional ya es un gran paso para futuros trabajos en los que se profundice sobre los deberes que tenemos como personas, para con nosotros mismos, nuestra comunidad (a nivel local, regional y nacional) e incluso con toda la humanidad (¿cosmopolitismo?), tanto presente como futura (prospectivamente). 